\title{
PENGARUH MODEL PEMBELAJARAN BERBASIS MASALAH DENGAN PENDEKATAN PROBLEM POSING TERHADAP KREATIVITAS MATEMATIKA DAN AKTIVITAS SISWA PADA MATERI KUBUS DAN BALOK KELAS VIII SMP NEGERI 7 POLEWALI
}

\author{
Ahmad Syah $^{1 *}$, Alimuddin², Ahmad Talib ${ }^{3}$
}

\begin{abstract}
The research aims on discovery the description and the influence of Problem Based Learning Model with Problem Posing Approach on mathematics creativity and Student Activity on The Material of Cubes and Beams of Class VIII Student at $S M P N 7$ Polewali. The research was free experiment research which employed one group pretest-posttest design. The result of research reveal that (1) the student' Mathematics creativities before applying problem based learning with problem posing approach to class VIII B student at SMPN 7 Polewali show that 23 student are in uncreative category and 1 student is less creativity category, the student' mathematics creativity after applying problem based learning with problem posing approach to class VIII B student at SMPN 7 Polewali shows that 1 student is in very creativity, 5 student are in creativity category, 17 student are in fairly creative category and 1 student is in less creativity category, (2) the description of the students' learning activity after applying problem based learning with problem posing approach to class VIII B student at SMPN 7 Polewali overall is in active category, (3) problem based learning with problem posing approach gives influence to class VIII B student at $S M P N 7$ Polewali with gain score in medium category.
\end{abstract}

Keywords: Problem Based Learning with Problem Posing Approach, Student' Mathematics Creativities, student activity

\section{PENDAHULUAN}

Pendidikan pada hakikatnya merupakan syarat mutlak bagi pengembangan sumber daya manusia dalam menuju masa depan yang lebih

*) Prodi Pendidikan Matematika, Universitas Al Asyariah Mandar.

E-mail: Ahmadsyah50@yahoo.com 
baik. Melalui pendidikan dapat dibentuk manusia yang mampu membangun dirinya sendiri dan bangsanya. Pendidikan merupakan suatu proses dimana proses tersebut memperoleh pengetahuan dan pemahaman melalui perubahan tingkah laku seseorang. Pendidikan adalah suatu tahapan kegiatan menyempurnakan perkembangan individu dalam menguasai pengetahuan, kebiasaan dan sikap. Maka dari itu perlu dilakukan peningkatan mutu pendidikan (Utomo, 2013: 6).

Peningkatan mutu pendidikan dapat dilakukan melalui beberapa cara, yaitu pengembangan kurikulum, peningkatan mutu lingkungan pengajar serta perbaikan sarana dan prasarana pendidikan. Cara-cara tersebut haruslah diperhatikan karena yang berperan aktif dalam pelaksanaan dan kegiatan kurikulum adalah guru, sedangkan yang berperan aktif sebagai subjek adalah siswa. Interaksi antara guru dengan siswa diperlukan agar tujuan pembelajaran yang diinginkan dapat tercapai. (Utomo, 2013: 6).

Matematika merupakan sarana berpikir deduktif dalam menemukan dan mengembangkan ilmu pengetahuan dan teknologi. Dewasa ini matematika tidak lagi dipandang sebagai ilmu pengetahuan dasar, tetapi lebih dari itu, matematika telah menjadi sarana untuk mengkaji hakikat keilmuan sehingga tidak dapat disangkal lagi bahwa untuk menunjang keberhasilan penguasaan ilmu pengetahuan dan tekologi peranan matematika sangat strategis dan menentukan. Matematika sebagai sarana berpikir ilmiah sangat diperlukan untuk menumbuhkan kemampuan berpikir kreatif, logis, sistematis dan teliti dalam diri siswa. Matematika juga merupakan dasar yang diperlukan siswa untuk menunjang keberhasilan belajarnya dalam menempuh pendidikan yang lebih tinggi. Bahkan matematika berperan dalam upaya meningkatkan sumber daya manusia dan sebagai tiang penopang perkembangan ilmu dan teknologi

Ahmad Talib ( 2014: 237 ) mengemukakan bahwa posisi guru dalam pembelajaran matematika adalah untuk mendiskusikan dan berkonsultasi dengan siswa, atau menginstruksikan siswa untuk berdiskusi dengan siswa lain dalam pembelajaran kelompok, mereka tidak dalam posisi untuk memberikan jawaban akhir yang tersedia. Makna diskusi dan negosiasi dalam kasus ini adalah membuat masalah rutin, atau memberi masalah berupa pertanyaan yang menantang siswa untuk berpikir lebih banyak dan mendiskusikan dan bernegosiasi lebih jauh untuk menyelesaikan masalah.

Dalam pembelajaran matematika di sekolah masih banyak guru yang menggunakan metode mengajar yang berpusat pada guru (teacher centered). Guru lebih mendominasi pembelajaran sehingga pembelajaran cenderung monoton. Siswa dijadikan objek pembelajaran dan guru berusaha memberikan 
informasi sebanyak-banyaknya, sehingga siswa tidak mempunyai kesempatan yang cukup untuk merenungkan apa yang diberikan oleh guru. Bagi mereka yang terpenting adalah dapat menyelesaikan soal-soal berdasarkan contohcontoh yang diberikan. Salah satu tujuan yang diharapkan yaitu seorang guru di sekolah dalam melaksanakan kegiatan belajar mengajar matematika yaitu mengaitkan setiap materi pelajaran yang diberikan dan penanaman konsep dasar yang kuat. Selain itu hal mendasar yang paling dituntut terhadap siswa dalam proses pembelajaran adalah kreativitas siswa dimana siswa mampu mengembangkan informasi yang berkaitan dengan matematika

Untuk mengatasi permasalahan-permasalahan yang terjadi, maka perlu adanya sesuatu pembelajaran yang dapat membelajarkan siswa dan memberikan kesempatan kepada siswa untuk dapat mengembangkan kreativitas belajarnya. Model pembelajaran yang dapat meningkatkan kreativitas belajar siswa yaitu model pembelajaran berbasis masalah dan pendeatan pembelajaran problem posing.

Pembelajaran berbasis masalah merupakan suatu pembelajaran yang menuntut aktivitas mental siswa untuk memahami suatu konsep pembelajaran melalui situasi dan masalah yang disajikan pada awal pembelajaran. Masalah yang disajikan pada siswa merupakan masalah kehidupan sehari-hari (kontekstual). Pembelajaran berbasis masalah ini dirancang dengan tujuan untuk membantu siswa mengembangkan kemampuan berpikir dan mengembangkan kemampuan dalam memecahkan masalah, belajar berbagai peran orang dewasa melalui keterlibatan mereka dalam pengalaman-pengalaman nyata.

Pendekatan pembelajaran problem posing dalam pembelajaran dapat melatih siswa untuk mengajukan pertanyaan-pertanyaan atau soal-soal yang berkaitan dengan materi yang dipelajari. Dalam pembelajaran yang menerapkan problem posing, perasaan tersebut dapat direduksi. Siswa dituntun untuk mengajukan masalah atau pertanyaan sesuai minat mereka dan memikirkan cara penyelesaiannya. Perhatian dan komunikasi matematika siswa melalui model pembelajaran problem posing akan lebih baik, karena pertanyaan atau soal yang berkualitas hanya mungkin dapat diajukan dan diselesaikan oleh siswa yang mempunyai perhatian sungguh-sungguh terhadap pelajaran matematika sehingga dapat memunculkan kreativitas siswa di dalam kelas. 


\section{METODE PENELITIAN}

Jenis penelitian ini adalah penelitian pra-eksperimen dengan pendekatan One Grup Pretest-Posttest Design. Penelitian ini akan menggunakan model PBL dengan pendekatan Problem Posing sebagai perlakuan terhadap kelas eksperimen.

\section{A. Desain Penelitian}

Adapun desain penelitian yang digunakan adalah pretest and postest only design ditunjukkan pada tabel 1 berikut:

Tabel 1. Desain Penelitian

\begin{tabular}{ccc}
\hline Pre-Test & Treatment & Post-Test \\
\hline $\mathrm{O}_{1}$ & $\mathrm{~T}$ & $\mathrm{O}_{2}$ \\
\hline
\end{tabular}

Sumber: Sugiyono (2012)

\section{B. Populasi dan Sampel}

Dalam penelitian ini yang menjadi populasinya adalah seluruh siswa kelas VIII SMP Negeri 7 polewali tahun pelajaran 2016/2017, yang terdiri dari kelas pararel dengan jumlah siswa 68. Sampel penelitian ini adalah kelas VIII B terdiri dari 24 siswa.

\section{HASIL DAN PEMBAHASAN}

\section{HASIL}

\section{Hasil Analisis Deskriptif}

a. Deskripsi keterlaksanaan penerapan model Problem Based Learning (PBL) dengan pendekatan Problem Posing dalam pembelajaran matematika

Hasil observasi keterlaksanaan pembelajaran dengan model Problem Based Learning (PBL) dengan pendekatan Problem Posing

Tabel 2. Hasil Observasi Keterlaksanaan Model PBL dengan pendekatan Problem Posing

\begin{tabular}{lll}
\hline Pertemuan & Rata-rata TKP & Kategori \\
\hline Pertemuan I & 3,63 & Terlaksana dengan baik \\
Pertemuan II & 4,00 & Terlaksana dengan baik \\
Pertemuan III & 4,31 & Terlaksana dengan baik \\
\hline
\end{tabular}




\begin{tabular}{lll}
\hline Pertemuan & Rata-rata TKP & Kategori \\
\hline Pertemuan IV & 4,50 & Terlaksana dengan baik \\
\hline
\end{tabular}

Berdasarkan Tabel 2, terlihat bahwa pada setiap pertemuan tingkat keterlaksanaan pembelajaran berada pada kategori terlaksana dengan baik. Dari rata-rata tingkat keterlaksanaan pembelajaran (TKP) juga terlihat adanya peningkatan terkait keterlaksanaan pembelajaran dengan model pembelajaran Problem Based Learning (PBL) dengan pendekatan Problem Posing yang diterapkan dalam penelitian ini.

b. Deskripsi aktivitas siswa dalam pembelajaran matematika menggunakan model Problem Based Learning (PBL) dengan pendekatan Problem Posing

Tabel 3. Kategori skor rata-rata aktivitas siswa

\begin{tabular}{ccccccc}
\hline Aspek & \multicolumn{4}{c}{ Pertemuan } & Rata-rata tiap & Kategori \\
& \cline { 2 - 4 } & I & II & III & IV & \\
\hline 1 & 2,17 & 2,67 & 2,50 & 2,84 & 2,55 & Aktif \\
2 & 2,00 & 2,84 & 3,00 & 3,34 & 2,80 & Aktif \\
3 & 2,67 & 3,00 & 2,67 & 2,84 & 2,80 & Aktif \\
4 & 2,17 & 2,50 & 2,50 & 3,00 & 2,54 & Aktif \\
5 & 2,34 & 2,67 & 3,00 & 2,34 & 2,59 & Aktif \\
6 & 3,17 & 3,34 & 3,17 & 3,34 & 3,26 & Aktif \\
\hline \multicolumn{6}{c}{ Rata-rata Total } \\
\hline
\end{tabular}

Berdasarkan Tabel 3, tampak bahwa kategori aktivitas siswa pada umumnya berada pada kategori aktif. Dengan demikian dapat disimpulkan bahwa aktivitas siswa dalam pembelajaran matematika dengan model Problem Based Learning (PBL) dengan pendekatan Problem Posing untuk keenam aspek yang diamati memenuhi kriteria yang telah ditetapkan pada Bab III dengan rata-rata total 2,76 yang berada pada kategori aktif.

c. Deskripsi hasil belajar matematika siswa menggunakan model Problem Based Learning (PBL) dengan pendekatan Problem Posing

Tabel 4. Distribusi dan persentase skor hasil kreativitasr matematika siswa (posttest)

\begin{tabular}{ccccc}
\hline No & Interval skor & Kategori & Frekuensi & Persentase (\%) \\
\hline 1 & $90-100$ & Sangat Tinggi & 1 & 4,17 \\
\hline
\end{tabular}




\begin{tabular}{cclcc}
\hline 2 & $80-89$ & Tinggi & 5 & 20,83 \\
3 & $65-79$ & Sedang & 17 & 70,83 \\
4 & $55-64$ & Rendah & 1 & 4,17 \\
5 & $0-54$ & Sangat Rendah & 0 & 0,00 \\
\hline \multicolumn{2}{l}{ Jumlah } & & 24 & 100,00 \\
\hline
\end{tabular}

Berdasarkan Tabel 4, dapat digambarkan bahwa dari 24 siswa kelas VIII B SMPN 7 polewali yang dijadikan sampel penelitian, pada umumnya memiliki tingkat hasil kreativitas matematika yang sedang.

Tabel 5. Hasil pengkategorian N-Gain siswa

\begin{tabular}{llll}
\hline Interval & Kategori & Frekuensi & Persentase (\%) \\
\hline$g \leq 0,3$ & Rendah & 0 & 0,00 \\
$0,3<g<0,7$ & Sedang & 21 & 87,5 \\
$g \geq 0,7$ & Tinggi & 3 & 12,5 \\
\hline
\end{tabular}

Berdasarkan Tabel 5, diperoleh bahwa 21 siswa berada pada kategori sedang dan 3 siswa berada pada kategori. Sehingga rata-rata N-Gain hasil belajar siswa adalah 0,62 yakni berada pada kategori sedang.

\section{Hasil analisis inferensial}

a. Uji normalitas

Hasil kreativitas matematika siswa

a) Hasil belajar matematika siswa kelas VIII.A SMPN 1 Saluputti, Kabupaten Tana Toraja setelah diajar menggunakan model PBL dengan pendekatan Problem Posing.

Berdasarkan hasil analisis data menggunakan Shapiro-Wilk Normality Test, untuk data posttest diperoleh $p=0,197$ sebagaimana ditunjukkan pada Tabel 6.

Tabel 6. Uji normalitas data posttest

\begin{tabular}{llll}
\hline & Shapiro-Wilk & & \\
\cline { 2 - 4 } Posttest & Statistic & Df & Sig. \\
& 0,947 & 24 & 0,271 \\
\hline
\end{tabular}


Karena p-value lebih dari $\alpha=0,05$, maka dapat disimpulkan bahwa $H_{0}$ diterima sehingga data posttest berasal dari populasi terdistribusi normal. Dengan demikian, uji-t dapat diterapkan.

b) Gain ternormalisasi siswa kelas VIII B SMPN 7 Polewali yang diajar menggunakan model PBL dengan pendekatan Problem Posing

Berdasarkan hasil analisis data menggunakan Shapiro-Wilk Normality Test, untuk data gain diperoleh $p=0,072$ sebagaimana ditunjukkan pada Tabel 7.

Tabel 7. Uji normalitas data gain

\begin{tabular}{llll}
\hline & Shapiro-Wilk & & \\
\cline { 2 - 4 } Gain & Statistic & Df & Sig. \\
& 0,922 & 24 & $0,072^{*}$ \\
\hline
\end{tabular}

*. This is a lower bound of the true significance.

Karena $p$-value lebih dari $\alpha=0,05$, maka dapat disimpulkan bahwa $H_{0}$ diterima sehingga data gain berasal dari populasi terdistribusi normal. Dengan demikian, uji-t dapat diterapkan.

b. Uji-t

Sebagaimana telah dikemukakan pada bab III bahwa uji-t digunakan untuk menguji hipotesis yang berkaitan dengan pengaruh penerapan model PBL dengan pendekatan Problem Posing pada kreativitas matematika siswa. Adapun hasil pengujian hipotesis adalah sebagai berikut.

1) Hasil kreativitas matematika siswa

a) Hasil kreativitas matematika siswa kelas VIII B SMPN 7 Polewali setelah diajar menggunakan model PBL dengan pendekatan Problem Posing.

Pengujian hipotesis menggunakan uji t satu sampel (one sample t-test) sebagaimana ditunjukkan pada Tabel 3.7.

Tabel 8. Uji t satu sampel data posttest

\begin{tabular}{|c|c|c|c|c|c|c|}
\hline & \multicolumn{6}{|c|}{ Test Value $=60$} \\
\hline & \multirow{3}{*}{$\mathrm{T}$} & \multirow{3}{*}{ df } & \multirow{3}{*}{$\begin{array}{l}\text { Sig. (2- } \\
\text { tailed) }\end{array}$} & \multirow{3}{*}{$\begin{array}{l}\text { Mean } \\
\text { Difference }\end{array}$} & $95 \%$ & Confidence \\
\hline & & & & & $\begin{array}{l}\text { Interval } \\
\text { Difference }\end{array}$ & of the \\
\hline & & & & & Lower & Upper \\
\hline Posttest & 4,134 & 23 & 0,000 & 8,88333 & 4,766 & 13,0007 \\
\hline
\end{tabular}


Hasil uji t satu sampel untuk data posttest pada Tabel 8, menunjukkan bahwa $\frac{p \text {-value (two tailed) }}{2}=0,0001<0,05=\alpha$, maka $H_{0}$ ditolak. Hal ini berarti bahwa siswa yang diajar melalui penerapan model pembelajaran berbasis masalah dengan pendekatan problem posing terhadap kreativitas matematika siswa berpengaruh pada siswa kelas VIII B SMP Negeri 7 Polewali.

b) Gain ternormalisasi siswa kelas VIII B SMP Negeri 7 Polewali yang diajar menggunakan model PBL dengan pendekatan Problem Posing

Pengujian hipotesis menggunakan uji t satu sampel (one sample t-test) sebagaimana ditunjukkan pada Tabel 9.

Tabel 9. Uji t satu sampel data gain

\begin{tabular}{|c|c|c|c|c|c|}
\hline & \multicolumn{5}{|c|}{ Test Value $=0,29$} \\
\hline & \multirow{3}{*}{$\mathrm{T}$} & \multirow{3}{*}{ Df } & \multirow{3}{*}{$\begin{array}{l}\text { Sig. } \\
\text { tailed) }\end{array}$} & \multirow{3}{*}{$\begin{array}{l}\text { Mean } \\
\text { Difference }\end{array}$} & Confidence \\
\hline & & & & & $\begin{array}{l}\text { Interval of the } \\
\text { Difference }\end{array}$ \\
\hline & & & & & Lower \\
\hline Gain & 16,493 & 23 & 0,000 & 0,31625 & 0,3559 \\
\hline
\end{tabular}

Hasil uji t satu sampel untuk data gain pada Tabel 9, menunjukkan bahwa $\frac{p \text {-value (two tailed) }}{2}=0,0001<0,05=\alpha$, maka $H_{0}$ ditolak. Hal ini berarti bahwa gain ternormalisasi siswa kelas VIII B SMP Negeri 7 Polewali yang diajar menggunakan model PBL dengan pendekatan Problem Posing berada pada kategori minimal sedang.

\section{PEMBAHASAN}

\section{Keterlaksanaan Pembelajaran}

Hasi Hasil observasi keterlakasanaan penerapan model pembelajaran berbasis masalah dengan pendekatan problem posing terhadap kreativitas matematika dan aktivitas siswa menunjukkan peningkatan dari tiap pertemuan hal ini dapat dilihat dari kegiatan awal, kegiatan inti dan kegiatan akhir pada setiap pertemuan. Pada kegiatan awal yaitu menggali pengetahuan awal siswa yang meliputi mengkondisikan kelas, mengkomunikasikan model dan tujuan pembelajaran, mempersiapkan pembelajaran dengan mengajukan pertanyaan yang berkaitan dengan kehidupan sehari-hari dan pengalaman siswa, pada setiap pertemuan kemampuan guru mencapai nilai minimal 3. Suatu pemahaman konsep itu bermakna jika dibangun dan dikaitkan dengan pengalaman hidup 
seseorang. Oleh karena itu, dengan mengaitkan pembelajaran dengan pengalaman hidup siswa pada awal pembelajaran memungkinkan peserta didik untuk mengenal konsep secara bermakna.

Pada kegiatan inti, nilai setiap aspek pada setiap pertemuan yang dicapai guru minimal 3 yang berarti cukup baik. Kemampuan guru yang ditekankan adalah kemampuan pada fase 3 dan fase 4 yaitu guru meminta siswa mendiskusikan masalah atau pertanyaan yang ada pada LKS yang sudah dibagikan dan menjelaskan konsep dengan kalimat mereka sendiri, dalam fase ini guru juga meminta siswa untuk mempresentasikan hasil pekerjaan mereka.

\section{Aktivitas Siswa}

Hasil observasi terhadap aktivitas siswa dengan penerapan model pembelajaran berbasis masalah dengan pendekatan problem posing terhadap aktivitas siswa menunjukkan bahwa rata-rata keenam kategori yang diamati berada dalam kategori aktif. Bentuk aktivitas siswa yang diharapkan tercapai, yaitu: (1) Memperhatikan/mendengarkan informasi/penjelasan guru, (2) Membaca dan memahami materi pelajaran pada buku siswa atau LKS, (3) Berinteraksi/ berdiskusi/ bekerjasama dengan teman dalam membuat soal dan menyelesaikan masalah yang ada dalam lembar kegiatan siswa, (4) Mempresentasikan hasil diskusi kelompok dan mengumpulkan LKS, (5) Mengerjakan kuis yang diberikan secara Individu, dan (6) Membuat atau mencatat rangkuman pelajaran/ kesimpulan dari materi yang telah dipelajari. Pencapaian ini menunjukkan bahwa aktivitas siswa yang diharapkan terpenuhi. Hal ini sesuai dengan indikator aktivitas yang diharapkan pada penerapan model pembelajaran berbasis masalah dengan pendekatan problem posing terhadap aktivitas siswa yang memberi kesempatan kepada siswa untuk mengkonstruksi sendiri pengetahuan yang dimilikinya.

\section{Hasil Kreativitas Matematika Siswa}

Berdasarkan skor pretest yang diperoleh sebelum menerapkan model pembelajaran berbasis masalah dengan pendekatan problem posing terhadap kreativitas matematika siswa menunjukkan bahwa tingkat kemampuan awal siswa rata-rata masih berada pada tahap rendah. Skor maksimum yang diperoleh siswa adalah 46,20 dari skor ideal 100. Namun, hasil kreativitas matematika siswa setelah diajar dengan penerapan model pembelajaran berbasis masalah dengan pendekatan problem posing terhadap kreativitas matematika siswa rata-rata berada pada kategori tinggi. kreativitas matematika siswa juga menunjukkan bahwa terdapat peningkatan signifikan setelah proses penerapan 
model pembelajaran berbasis masalah dengan pendekatan problem posing terhadap kreativitas matematika siswa. Hal tersebut ditunjukkan dari nilai gain yang diperoleh siswa yakni 0,62 yang berada pada kategori sedang. Peningkatan tersebut tidak lepas dari kompleksitas pembelajaran dengan penerapan model pembelajaran berbasis masalah dengan pendekatan problem posing terhadap kreativitas matematika siswa. Hasil penelitian ini juga menunjukkan peningkatan tingkat kreativitas siswa dalam membuat soal, hal itu terlihat pada lembar kerja siswa dimana siswa merancang sebuah masalah dalam bentuk soal matematis kemudian soal yang dirancang tersebut memiliki cara penyelesaian dan jawaban yang banyak. Soal dirancang sedemikian rupa sehingga dapat memenuhi kedua indikator kreativitas dalam penelitian ini. Peningkatan itu juga terlihat pada posttest, terdapat 12 siswa yang mampu menyelesaikan soal yang memenuhi indikator kelancaran dan juga keluwesan, sedangkan pada saat tes awal belum ada satupun siswa yang mampu menyelesaikan soal dengan beragam cara maupun cara penyelesaian yang beragam.

\section{SIMPULAN}

Berdasarkan hasil penelitian dan pembahasan, maka kesimpulan dalam penelitian ini sebagai berikut:

1. Kreativitas matematika siswa sebelum diterapkan model pembelajaran berbasis masalah dengan pendekatan problem posing pada siswa kelas VIII B SMP Negeri 7 Polewali berada pada kategori sangat rendah sebannyak 23 siswa dan pada kategori rendah sebanyak 1 siswa Sedangkan Kreativitas matematika siswa setelah diterapkan model pembelajaran berbasis masalah dengan pendekatan problem posing pada siswa kelas VIII B SMP Negeri 7 Polewali berada pada kategori sangat tinggi sebannyak 1 siswa, pada kategori tinggi sebanyak 5 siswa, pada kategori sedang sebanyak 17 siswa dan pada kategori rendah sebanyak 1 siswa.

2. Deskripsi aktivitas belajar siswa setelah diterapkan model pembelajaran berbasis masalah dengan pendekatan problem posing pada siswa kelas VIII B SMP Negeri 7 Polewali secara keseluruhan berada pada kategori aktif.

3. Model pembelajaran berbasis masalah dengan pendekatan problem posing berpengaruh terhadap kreativitas dan aktivitas pada siswa kelas VIII B SMP Negeri 7 Polewali.

\section{SARAN}

Berdasarkan kesimpulan yang dikemukakan di atas, maka terdapat saran yang perlu disampaikan sebagai berikut. 
1. Pembelajaran matematika dengan menerapkan model pembelajaran berbasis masalah dengan pendekatan problem posing perlu dipertimbangkan sebagai salah satu sarana untuk dapat meningkatkan kreativitas matematika pada siswa.

2. Guru dapat menerapkan model pembelajaran berbasis masalah dengan pendekatan problem posing dalam menfasilitasi aktivitas siswa dan meningkatkan kreativitas matematika pada siswa.

3. Untuk penelitian selanjutnya, bagi peneliti yang berminat mengembangkan penelitian ini, diharapkan mencermati keterbatasan penelitian ini, sehingga penelitian selanjutnya dapat menyempurnakan hasil penelitian ini.

Agar kreativitas matematika siswa dapat mencapai hasil maksimal, diharapkan penelitian seperti ini seyogyanya juga dilakukan pada pokok bahasan lain, sehingga membuat siswa tertarik, senang dan aktif belajar matematika.

\section{DAFTAR PUSTAKA}

Abuddin, Nata. 2009. Perspektif Islam Tentang Strategi Pembelajaran. Jakarta: Kencana.

Aisyah, Nyimas.2012. Pengembangan Pembelajaran Matematika. Direktorat Jenderal Pendidikan Tinggi.

Amarta, Risye. 2013. Agar Kamu Menjadi Pribadi Kreatif. Yogyakarta: PT. Niaga

Aqib, Zainal. 2013. Model-Model, Media dan Strategi Pembelajaran Konsektual (Inovatif). Bandung : CV Yrama Widya.

Arikunto, Suharsimi. 2012. Penelitian Tindakan Kelas. Jakatra : PT Bumi Aksara.

Budiningsih, Asri. 2015. Belajar dan Pembelajaran. Jakarta: Rineka Cipta.

Djumanta, Wahyuddin \& Dwi Susanti. 2008. Belajar Matematika Aktif dan Menyenangkan. Bandung : Pusat pembukuan Departemen pendidikan Nasional.

Hobri. 2009. Model-model Pembelajaran Inovatif. Jember: Center of Society Studies. (http://abdulkhakim-kurniawan. Blogspot.com. diakses pada 23 Januari 2017.

Huda, Nurul. 2010. Strategi Pembelajaran. Jakarta Barar. PT. Multi Kreasi Satudelapan. 
Hudoyo, Herman. 1990. Strategi Belajar Mengajar Matematika. Malang: IKIP Malang

Iskandar. 2012. Psikologi Pendidikan. Jakarta : Ciputat Mega Mall.

Kunandar. 2011. Langkah Mudah Penelitian Tindakan Kelas Sebagai Pengembangan Profesi Guru. Jakarta : PT Raja Grafindo Persada.

Miyanto \& Suparno dkk. 2012/2013. Detik Detik Ujian Nasional Matematika. Jakarta: Intan Pariwara.

Moniarti, Rika. 2010. Kreasi Matematika Cilik. Jakarta : Sinergi pustaka Indonesia.

Naim, Ngainum. 2016. Menjadi Guru Inspiratif Memberdayakan dan Mengubah Jalan Hidup Siswa. Yogyakata: Pustaka pelajar.

Noor, Muhammad. 2010. Paikem Gembrot (Pembelajaran Aktif Inovatif Kreatif Efektif Menyenangkan Gembira dan Berbobot). Jakarta : Multi Kreasi Satu delapan.

Nurkencana, Wayan \& Sunartan. Evaluasi hasil Belajar. Surabaya: Usaha Nasional.

Rahman, Abdul. 2013. The Profile of Students' Mathematical Problem Posing Based on Their Cognitive Styles.Volume 3. FMIPA Universitas Negeri Makassar. Indian Streams Research Journal.

Roestiyah. 2012. Strategi Belajar Mengajar. Jakarta : Rineka Cipta.

Rosli, Roslinda dkk. 2014. The Effect on Problem Posing on Student Mathematical Learning: A Meta-Analysis. Volume 7. The Nasional University of Malaysia. Canadian Center of Science and Education.

Rusman. 2012. Model-model Pembelajaran Mengembangkan Profesionalisme Guru. Jakarta. Rajawali pers.

Sanjaya, Wina. 2006. Strategi Pembelajaran Berorientasi Standar Proses Pendidikan. Jakarta: Kencana.

Siswono, Tatang Eko Yuli. 2013. Pembelajaran Matematika yang Menumbuhkan Tindak Berpikir Kreatif. FMIPA: UNESA.

Slameto. 2010. Belajar dan Faktor-faktor yang Mempengaruhinya. Jakarta : Rineka cipta.

Sudjana, Nana. 2010. Cara Belajar Siswa Aktif dalam Proses Belajar Mengajar. Bandung : Sinar Baru Algensindo.

Sugiyono. 2010. Metode Penelitian Pendidikan Pendekatan Kuantitatif Kualitatif, dan R\&D.Bandung: CV. Alfabeta.

Sukino \& Simangunson, Wilson. 2006. Matematika untuk SMP kelas VIII. Jakarta : Erlangga.

Sundayana, Rostina. 2014. Statistika Penelitian Pendidikan. Bandung: Alfabeta. 
Syah, Muhibbin. 2014. Psikologi Pendidikan dengan Pendekatan Baru. Bandung: PT Remaja Rosda Karya.

Talib, ahmad \& kailani ismail. 2014. Problem Based Learning Model in Cooperative Situation (PBLCS) and Its Impact on Development of Personal Intelegence. Volume 3. University teknologi Malaysia. Internasinal Journal of Evaluation and Research in Education.

Tiro, M Arif. 2008. Dasar-dasar Stistika. Makassar: Andira Publisher.

Trianto. 2010. Mendesain Model Model Pembelajaran Inovativ-Progresif. Jakarta: Kencana Prenada Media Group.

Wahyuni, Shanti.2010. Bangun Ruang Sisi Lengkung. Bekasi : Adhi Aksara Abadi Indonesia.

Winataputra, Udin,S. 2009. Teori Belajar dan Pembelajaran. Jakarta: Universitas Terbuka. 